\title{
Pengelolaan Dream Island Sebagai Daya Tarik Wisata Pantai, Di Mertasari, Desa Sanur Kauh, Kecamatan Badung, Bali
}

Martha Edlyn Marintan Hutagalunga, 1 , Dian Pramita Sugiartia, 2

1marthaedlyn@gmail.com,2dian_pramita@unud.ac.id

a Program Studi Sarjana Destinasi Pariwisata, Fakultas Pariwisata, Universitas Udayana, Jl. Dr. R. Goris, Denpasar, Bali 80232 Indonesia

\begin{abstract}
This research have a purpose for to know about the management system and condition of $4 A$ (Atraction, Accesibility, Amenity and Anciliary) from the Tourist Attraction of Dream Island Beach. The qualitative Method with the data sources from primary data and secondary data used to collect data. The Primary data of this research is the data that was come from the observation and interview, while the secondary one come from documentary or literature study to complete the primary data. The technique to choose the informant that was being used is Purpose Sampling. The result of this research pointed that the management system of Dream Island Beach didn't went smoothly, because the planning system not reach the maximum point. The organization system already went smoothly, and all of the staff already put on their position according to their responsibility over their task. The connection between manager and the staff already on good terms, and the condition of tourist attraction on this beach already in good terms with many attraction inside the beach. The accessibility on this tourist destination still need more improvements especially on Toilet whom inadequate. The Anciliary or the institution on the Dream Island beach already reach the average point.
\end{abstract}

Keywords: Management, Dream Island Beach, Beach Tourism.

\section{PENDAHULUAN}

Bali merupakan salah satu provinsi yang turut andil dalam pengembangan sektor pariwisata, sektor pariwisata di Pulau Bali menjadi penggerak mulai dari tahun 1970-an. Oleh karena itu kepariwisataan merupakan bagian yang sangat melekat dan tidak dapat dipisahkan lagi dalam kehidupan masyarakat dan pada pembangunan di Pulau Bali.

Budaya Bali menjadi istimewa karena tidak dapat dijumpai di daerah asal wisatawan. Wisatawan tertarik berkunjung karena ciri khas budaya Bali dengan keunikan tradisinya yang sulit ditemui di tempat lain (Anom, dkk, 2020).

Perkembangan kepariwisataan Bali kini telah mengalami kemajuan yang pesat, baik dari segi kuantitas maupun kualitas. Bali juga menjadi sasatan investor karena Bali memiliki banyak obyek daya tarik wisata dengan ragam potensinya (Hariyana, dkk., 2015).

Selain budaya, keindahan alam mulai dari keindahan pegunungannya dan juga keindahan pantainya. Salah satu Daya Tarik Wisata pantai yang terkenal adalah terdapat pada kawasan Sanur yang letaknya persis di sebelah timur Kota Denpasar. Karena pantai Sanur dikenal memiliki ombak yang cukup tenang sehingga kebanyakan wisatawan yang berkunjung ke pantai ini bukan untuk melakukan surfing melainkan untuk menikmati keindahan dan ketenangan pantainya. Pantai Sanur juga terkenal sebagai Sunrise Beach atau pantai matahari terbit, sehingga banyak wisatawan yang berkunjung dipagi hari untuk menikmati pemandangan matahari terbit.

Terdapat salah satu pantai yang unik yaitu Dream Island yang merupakan bagian dari Pantai Mertasari. Pantai Dream Island sendiri baru berdiri selama tiga tahun yang 
lalu. Maka dari itu penelitian ini bertujuan untuk mengetahui sejauh mana pengelolaan dan kondisi 4A (atraksi, amenitas, aksesibilitas dan anciliary) pada Pantai Dream Island.

Rumusan masalah yang dikemukakan dalam penelitian ini adalah mengenai bagaimana pengelolaan Pantai Dream Island dan bagaimana kondisi 4A (atraksi, amenitas, aksesibilitas dan anciliary) pada Pantai Dream Island.

\section{TINJAUAN PUSTAKA}

\subsection{Telaah Hasil Penelitian Sebelumnya.}

Penelitian yang dilakukan oleh Permilasari (dkk., 2014), berjudul "Bentuk Pengelolaan Pantai Batu Bolong Sebagai Daya Tarik Wisata Surfing di Desa Canggu, Kecamatan Kuta Utara, Kabupaten Badung", penelitian ini membahas mengenai pengelolaan daya tarik wisata. Penelitian selanjutnya dilakukan oleh Muliadi (dkk., 2016) berjudul "Pengelolaan Museum Arma sebagai Daya Tarik Wisata Budaya di Desa Ubud", penelitian ini membahas mengenai pengelolaan daya tarik wisata budaya. Penelitian selanjutnya dilakukan oleh Ani Rahmawati yang berjudul "Pengelolaan Kawasan Pesisir Untuk Kegiatan Wisata Pantai dan Perikanan di Kecamatan Pringkulu, Kabupaten Pacitan, Provinsi Jawa Timur", penelitian ini membahas mengenai pengelolaan kawasan pesisir pantai.

\subsection{Landasan Teori dan Konsep}

Untuk menganalisis permasalahan yang terdapat pada penelitian ini, menggunakan teori dan konsep yaitu teori manajemen dari G.R Terry, 1990 yang terbagi menjadi empat bagian; Planning (Perencanaan), Organizing (Pengorganisasian), Actuating (Pelaksanaan) dan Controlling (Pengawasan) atau disingkat dengan POAC dan konsep 4A (Attraction, Amenities, Access, Anciliary) (Cooper, 1995).

\section{METODE \\ Penelitian ini menggunakan} paradigma penelitian kualitaif dengan metode kualitatif dan teknik pengumpulan data kualitatif (Anom, dkk., 2020;
Mahagangga, 2020). Jenis data yang digunakan dalam penelitian ini adalah data kualitatif dan kuantitatif (Nazir, 1988). Sumber data yakni data primer dan sekunder (Sugiyono, 2003). Teknik penentuan informan menggunakan Purposive sampling. Purposive (Mukhtar, 2013). Data yang diperoleh dalam penelitian ini melalui teknik pengumpulan data observasi (Suryawan,dkk.,2017),wawancara(Sugiyono, 2014) dan studi dokumentasi (Moleong, 2002). Teknik analisis data menggunakan teknik analisi data kualitatif dengan penyajian data secara deskriptif (Miles dkk., 1992).

\section{HASIL DAN PEMBAHASAN 4.1 PENGELOLAAN DAYA TARIK WISATA PANTAI DREAM ISLAND}

Pantai Dream Island merupakan Daya Tarik Wisata yang dikelola oleh pihak swasta yang berada dibawah naungan Desa Pakraman Intaran Sanur. Hal ini karena lahan yang digunakan oleh pengelola Pantai merupakan lahan dari Desa Pakraman Intaran, peranan Desa tidak hanya sampai disitu saja melainkan juga memberi sejumlah tenaga kerja untuk bekerja di pantai ini. Pantai Dream Island dibangun dengan konsep yang sangat berbeda dengan pantai lainnya. Konsep berbeda sengaja diusung di Pantai ini, agar menarik minat kunjungan wisatawan.

Pantai Dream Island merupakan satusatunya pantai yang menawarkan beragam atraksi didalamnya, sehingga pada satu tempat wisatawan dapat menikmati beragam atraksi dalam satu hari. Pada pantai ini dibentuk suatu struktur organisasi yang memudahkan untuk mengetahui fungsi dan tanggungjawab masing-masing dalam menjalankan pengelolaan Pantai Dream Island.

\begin{tabular}{lcr}
\multicolumn{2}{c}{ Berdasarkan hasil penelitian } \\
pengelolaan Pantai & Dream & Island \\
berdasarkan fungsi manajemen yaitu & manning, organizing, actuating and \\
planning androlling sebagai berikut: &
\end{tabular}




\section{PERENCANAAN (PLANNING)}

Sejauh ini hal yang dilakukan dan akan dilakukan untuk mencapai target yang ditetapkan adalah dengan cara melakukan promosi pada media sosial baik pada website, facebook, maupun Instagram. Dan rencananya pihak pengelola Pantai Dream Island juga akan membuat pamphlet 3D (tiga dimensi) menggunakan lampu LED (Light Emitting Diode) dimana pamphlet tersebut akan dirancang dengan keseluruhan menggunakan lampu, dan ditempatkan didepan pintu masuk atau pintu pengambilan tiket.

Disini dijelaskan bahwa Desa berperan penting dalam keberlangsungan kegiatan wisata ini karena Desa sangat membantu dalam penyedian tempat. Apabila Desa tidak memberi perizinan untuk pembukaan Daya Tarik Wisata ini maka otomatis Pantai Dream Island tidak bisa berdiri. Pihak Desa juga membantu dalam mencari jumlah tenaga kerja dengan cara menyebarkan info ke Banjar di daerah Sanur Kauh.

\section{PENGORGANISASIAN(ORGANIZING)}

Untuk pelanggaran peraturan kerja yang dilakukan karyawan biasanya akan diberikan surat panggilan pertama dan surat panggilan kedua, apabila setelah surat panggilan kedua karyawan tersebut masih terbukti melanggar peraturan maka akan dikenakan sanksi berupa pemberhentian kerja.

Pantai Dream Island setiap bulannya melakukan evaluasi, dan guna dari evaluasi tersebut adalah agar semua pekerja baik atasan dan bawahan menyampaikan apa saja kekurangan dan permasalahan yang dilalui selama satu bulan tersebut, kemudian kedua belah pihak baik pihak atasan maupun bawahan mencari solusi untuk menyelesaikan kekurangan dan permasalahan yang ada.

Dalam manajemen Pantai Dream Island, sistem naik pangkat atau promosi tidak diberlakukan disini. Akan tetapi disini diberlakukan sistem penghargaan berupa bonus kepada karyawan teladan. Untuk gaji karyawan sesuai dengan kesepakatan awal antara karyawan dengan pihak pengelola. Karyawan juga mendapatkan THR (Tunjangan Hari Raya) yang diberikan setiap setahun sekali. Jumlah keseluruhan karyawan di Pantai Dream Island sebanyak 53 Orang.

\section{PENGGERAKAN (ACTUATING)}

Dalam pengelolaan Pantai Dream Island, sistem yang diterapkan adalah sistem kekeluargaan dan tidak ada perbedaan antara atasan dengan bawahan. Akan tetapi pada saat bekerja karyawan harus tetap bersikap professional. Potret kepemimpinan organisasi di Pantai Dream Island berjalan melalui pendekatan yang bersifat kekeluargaan, sehingga karyawan yang bekerja di Pantai ini merasa diperhatikan dan diayomi oleh pemimpinnya. Kegiatan yang kerap dilakukan oleh pengelola untuk meningkatkan solidaritas dan keakraban mereka adalah dengan melakukan rangkaian kegiatan yang dilaksanakan pada ulang tahun Pantai Dream Island.

\section{PENGAWASAN (CONTROLING)}

Berdasarkan hasil wawancara dapat diketahui bahwa standar pelaksanaan adalah patokan bagi pihak pengelola sebagai tolak ukur dalam mengelola Pantai Dream Island. Para pengelola mengawasi segala berjalannya kegiatan yang ada di Pantai Dream Island, terutama dalam penangkaran ikan hiu dimana tim monitoring akan selalu memeriksa bagaimana keadaan dari hiu tersebut dan apabila hiu tersebut sudah bisa dilepaskan kembali ke habitatnya maka akan segera dikoordinasikan dengan pihak pengelola agar segera dilakukan pelepasan terhadap hiu. Pemeriksaan kesehatan terhadap unta dan kuda juga dilakukan sebulan sekali agar unta dan kuda tersebut dapat dipastikan baik-baik saja, dan apabila ada permasalahan dengan kesehatan unta dan kuda agar dapat langsung dilakukan perawatan.

Mengingat Pantai Dream Island adalah suatu daya tarik wisata dan juga tempat 
pemotretan prewedding yang mana kenyamanan pengunjung juga harus diperhatikan, permasalahan sampah ini merupakan permasalahan yang sulit diatasi dan diperlukan sinergi antara pihak pengelola, masyarakat, dan juga pemerintah untuk secepatnya mengatasi kendala tersebut. Tentang pelaksanaan pengelolaan pak Ida Bagus Wasika menyatakan bahwa pelaksanaannya sudah berjalan sesuai dengan alur yang direncanakan dari awal. Pihak pengelola juga berharap ditahun berikutnya jumlah pengunjung ke Pantai Dream Island ini bisa meningkat dan menjadi salah satu Daya Tarik Wisata yang sangat diminati oleh wisatawan.

\subsection{KONDISI 4A PADA PANTA DREAM ISLAND \\ Aspek Atraksi (attraction)}

Aspek atraksi yang berkaitan dengan what to see adalah keindahan pantai yang asri dan penataan Pantai Dream Island berbeda dengan pantai lainnya, dipantai ini terdapat ayunan di tepi pantai dan juga lumbung-lumbung spa yang biasanya dijadikan tempat untuk berfoto. Keindahan wisata bahari yang terdapat di Pantai Dream Island adalah menikmati keindahan bawah laut dan juga kita bisa melihat penangkaran hiu yang ada di Pantai Dream Island.

Sedangkan aspek atraksi yang berkaitan dengan what to do atau apa yang dapat dilakukan adalah, pengunjung disana dapat melakukan kegiatan air disana seperti snorkeling, sepeda air, cano, berkeliling pantai dengan bersepeda, berkeliling pantai dengan menunggang kuda dan juga berkeliling pantai dengan menunggang unta. Kegiatan yang dapat dilakukan di Pantai Dream Island ditawarkan dengan harga yang berbeda-beda mulai dari paket snorkeling dan melihat hiu dikenakan biaya sebesar Rp50.000, penyewaan sepeda Rp50.000 menunggang kuda dan unta dikenakan sebesar Rp 100.000/25 menit. Tiket masuk menuju Pantai ini yakni sebesar Rp20.000 untuk orang dewasa dan Rp15.000 untuk anak-anak, nantinya tiket akan ditukarkan ke restoran untuk mendapat segelas welcome drink dan snack berupa kacang.

Aspek Aksesibilitas (accesibility)

Berdasarkan hasil observasi yang dilakukan oleh peneliti akses menuju Pantai Dream Island mulai dari pusat kota Denpasar sampai pada jalan sebelum memasuki gang pantai dream island sudah cukup bagus karena jalannya sebagian beraspal. Namun pada saat memasuki tempat parkir jalannya masih berbatu dan belum diaspal, namun itu bukan bagian dari pihak pengelola melainkan bagian dari pemerintah. Untuk menuju kelokasi ini wisatawan bisa menyewa kendaraan pribadi ataupun menggunakan jasa angkutan online, namun bagi jasa angkutan online tidak diperbolehkan sampai tepat di depan gerbang Pantai Dream Island, melainkan harus berjarak 100 Meter dari lokasi. Salah satu kendala adalah tidak adanya plang, baliho ataupun penunjuk lokasi Dream Island sendiri, sehingga untuk yang baru pertama kali berkunjung agak sedikit mengalami kesusahan mencari gang masuk menuju Pantai Dream Island ini.

\section{Aspek Amenitas (amenity)}

Berdasarkan hasil observasi yang dilakukan oleh peneliti, ketersediaan tempat parkir sudah cukup baik dan lahan parkirnya juga sangat cukup luas. Namun ketersedian toilet sangat terbatas, hanya ada 4 bilik toilet umum yang disediakan oleh pihak pengelola sehingga apabila pengunjung sedang ramai akan sangat lama menunggu antrean toilet. Ketersediaan bilik berganti pakaian juga sudah cukup memadai untuk bilik wanita tersedia 5 dan pria juga 5 maka total keseluruhan ada 10 bilik untuk mengganti pakian. Disana juga disediakan 30 loker yang dipinjamkan secara cuma-cuma kepada wisatawan. Restoran yang terdapat di pantai ini juga cukup tertata rapi dan bersih dengan menu makan siang juga makan malam, hal tersebut karena memang pantai ini memiliki paket bersantap malam sembari menikmati situasi matahari tenggelam, kekurangannya menu untuk makan pagi dan menu penutup belum disediakan oleh pihak pengelola. 
Tempat untuk memanjakan diri seperti spa juga tersedia di Pantai ini yang terdiri dari 10 lumbung spa dimana seluruh lumbung tersebut menghadap kepantai, sehingga ketika pengunjung yang melakukan spa juga bisa memandangi keindahan Pantai Dream Island. Pantai Dream Island juga memiliki panggung kecil yang biasanya digunakan sebagai tempat untuk pertunjukan, karena setiap paket makan malam wisatawan akan disuguhkan pertunjukan tarian Bali dan juga drumstick dancer. Selain itu itu panggung yang disediakan juga untuk penyewaan event-event seperti ulang tahun, gathering, dan juga resepsi pernikahan. Pantai ini juga menyediakan taman bermain (playground) untuk anak-anak yang tidak terlalu tertarik menikmati atraksi lain.

\section{Aspek Anciliary}

Pantai Dream Island dikelola oleh pihak swasta. Dan untuk kelembagaan atau organisasi didalamnya terdapat Desa Pakraman Intaran menjadi payung didalam pengelolaan Pantai Dream Island, kemudian kelembagaan yang berupa organisasi dalam jabatan tertinggi hingga yang paling bawah. Dikarenakan lahan ini merupakan lahan milik desa sehingga segala rencana yang hendak dilakukan harus dilaporkan ke desa dan menunggu persetujuan dari desa.

\section{Pengelolan Pantai Dream Island}

Pengelolaan Pantai Dream Island sepenuhnya dilakukan oleh pihak swasta. Dan masyarakat lokal disekitar Sanur Kauh yang menjadi karyawan dari daya tarik wisata ini. Susunan keorganisasian yang ada di tempat ini tidak jauh berbeda dengan susunan organisasi yang ada di perusahaan pada umumnya. Desa berperan penting dalam berjalannya daya tarik wisata ini, karena lahan dari Pantai Dream Island sendiri merupakan bagian dari desa dan apabila pantai ini disewa untuk acara besar seperti acara pernikahan, ulang tahun dan gathering maka pihak desa akan mengutus beberapa warganya untuk membantu pihak security menjaga keamanan. Keuntungan yang diberikan kepada desa adalah hasil penjualan tiket yang nantinya akan dibagi dua dimana pihak pengelola mendapatkan setengah bagian dan pihak Desa juga mendapat setengah bagian.

Pihak pengelola Pantai Dream Island menetapkan tugas dan tanggung jawab serta peraturan kerja bagi masing-masing departemen agar seluruh departemen dan karyawan bisa melaksanakan tugas dan tanggung jawabnya dengan baik dan secara profesional. Meski begitu sistem kekeluargaan sangat dijunjung tinggi di daya tarik ini guna meningkatkan rasa kepemilikan terhadap Pantai Dream Island dan lingkungan sekitarnya, sehingga tercipta kerjasama yang baik untuk mencapai tujuan awal yaitu menjadikan Pantai Dream Island sebagai daya tarik wisata yang wajib dikunjungi oleh wisatawan. Yang menjadi daya tarik pantai ini adalah di setiap hari sabtu dan minggu diadakan night market serta live performance dari $d j$ yang masingmasing harinya pihak pengelola menetapkan tema. Pada hari sabtu tema yang digunakan adalah pirates maka dari itu seluruh karyawan akan mengenakan kostum pirates dan mendekorasi lingkungan pantai dengan tema pirates. Pada hari minggu tema yang digunakan adalah zaman purba sehingga seluruh karyawan akan mengenakan kostum zaman purba serta mendekorasi lingkungan pantai dengan tema zaman purba juga. Hal ini menjadikan Pantai Dream Island berbeda dengan pantai lainnya.

Tentunya ada kendala yang dihadapi pada daya tarik wisata ini, kendala yang dihadapi pihak pengelola pada pantai ini adalah banyaknya sampah kiriman dari laut yang datang setiap hari. Sehingga menyebabkan beberapa kali daya tarik wisata ini ditutup untuk sementara waktu. Kendala sampah ini merupakan permasalahan yang rumit bagi pihak pengelola karena dengan banyaknya sampah kiriman yang datang maka itu akan sangat mengganggu kenyamanan dari wisatawan. Pantai Dream Island memiliki 15 orang yang bertugas dalam kebersihan pantai, 
dan satu tahun belakangan ini jumlah petugas sudah memadai dalam menangani kendala sampah secara perlahan. Pengelolaan disini juga lebih menonjolkan atraksi tarian bali, drumstick dance dan live dj yang dinikmati pada saat menunggu matahari tenggelam dan menikmati makan malam. Pelaksanaan pengelolaan Pantai Dream Island yang dikelola oleh pihak swasta sudah memenuhi kriteria yang terdapat pada teori manajemen G.R Terry yakni POAC (Planning, Organizing, Actuatting and Controlling).

\section{Kondisi 4A pada Pantai Dream Island}

Atraksi yang terdapat pada daya tarik wisata ini cukup beragam dan unik dimana pada bibir pantai terdapat ayunan yang bisa dijadikan atraksi berfoto bagi para wisatawan, terdapat pula unta dan kuda yang dapat disewa oleh wisatawan untuk berkeliling pantai ini, penyewaan sepeda, snorkeling, sepeda air, kegiatan spa dan yang tak kalah menarik adalah melihat penangkaran hiu. Pihak pengelola sangat ingin mengembangkan atraksi lain pada pantai ini, seperti pembuatan Konservasi Penyu dan membangun kolam berenang serta bar untuk menjadikan pantai ini mirip seperti beach club namun masih terkendala izin dari pihak desa.

Akses untuk menuju ke Pantai Dream Island sudah cukup baik karena akses jalan yang dimiliki sebagian sudah teraspal kecuali lokasi parkir belum teraspal dan berbatu. Untuk menuju ke tempat ini juga mudah diakses dengan kendaraan pribadi namun tidak ada kendaraan umum yang melewati atau melintasi kawasan ini karena di Bali kendaraan umum hanya disediakan di area tertentu. Kekurangannya juga terletak pada papan penunjuk arah yang tidak disediakan sehingga membuat wisatawan yang berkunjung tidak tahu letak persis pantai ini.
Amenitas merupakan fasilitas pendukung dimana fasilitas yang terdapat di pantai ini sudah cukup lengkap mulai dari restoran, taman bermain anak, lapangan mini futsal, tempat spa, toilet dan ruang ganti pria dan wanita. Namun yang menadi kekurangannya ialah jumlah toilet yang sangat terbatas sehingga apabila sedang ramai pengunjung maka pengunjung akan lama mengantri giliran untuk ke toilet.

Kelembagaan yang terdapat pada pantai ini merupakan pihak desa karena lahan yang digunakan merupakan bagian dari desa, sehingga untuk masalah perizinan harus ada pelaporan dan persetujuan dari pihak desa. Kemudian untuk kelembagaan yang terdapat di pantai ialah yang sudah ditetapkan berdasarkan struktur organisasi.

\section{Simpulan}

Berdasarkan hasil dan pembahasan dari penelitian maka simpulan yang diperoleh sebagai berikut:

1. Pihak pengelola Pantai Dream Island harus meningkatkan perhatian terhadap aspek kebersihan pantai, memperhitungkan sampah kiriman, menambahkan menu makanan untuk breakfast dan dessert sesuai dengan muatan lokal-ciri khas Sanur dan berkoordinasi-bersinergi dengan pemerintah desa dan masyarakat lokal dalam meningkatkan upaya promosi.

2. Pihak pengelola Pantai Dream Island Pemerintah Desa Sanur dan masyarakat lokal dapat pro aktif mengupayakan terciptanya daya tarik wisata yang berkelanjutan dan harmonis.

\section{DAFTAR PUSTAKA}

\footnotetext{
Amanah, Siti, Hamidah N. Utami, dan Tifa L. Savitri.2005. Perilaku Nelayan dalam Pengelolaan Wisata Bahari di Kawasan Pantai Lovina, Kabupaten Buleleng, Provinsi Bali. Laporan Kegiatan. Fakultas Perikanan. Institut Pertanian Bogor.

Anom, M.Par., Dr. Drs. I Putu dan Mahagangga, S.Sos.,M.Si, I Gusti Agung Oka. 2020. Handbook Ilmu Pariwisata
} 
Karakter dan Prospek. Jakarta: Prenada Media Group (Divisi Kencana)

ANOM, IPT et al. Case study of Balinese tourism: Myth as cultural capital. Utoía y Praxis Latinoamericana , [SI], v. $25, \quad$ p. $122-133$, Aug. 2020 ISSN 24779555. Available at: $<$ https://produccioncientificaluz.org/index.php/uto pia/article/view/33515 > Date accessed: 31 oct. 2020

Arjana, I Gusti Bagus. 2016. Geografi Pariwisata dan Ekonomi Kreatif. Edisi 1. 2. Rajawali Pers. Jakarta.

Bungin, Burhan. 2012. METODOLOGI PENELITIAN KUALITATIF.

Cooper, dkk. 1995. Tourism Principles and Practice. Prentice Hall. Harlow.

Hamidi, 2008. METODE PENELITIAN KUALITATIF (Pendekatan Praktis Penulisan Proposal dan Laporan Penelitian). Malang : UMM Press.

Hariyana, I. K., \& Mahaganggaa, I. G. A. O. (2015). Persepsi Masyarakat Terhadap Pengembangan Kawasan Goa Peteng Sebagai Daya Tarik Wisata Di Desa Jimbaran Kuta Selatan Kabupaten Badung. Jurnal Destinasi Pariwisata ISSN, 2338, 8811.

Hasibuan, Malayu. 2000. Manajemen Sumber Daya Manusia. Edisi Revisi. Jakarta: PT Bumi Aksara.

Kusmayadi dan Endar Sugiarto. 2000. Metodologi Penelitian dalam Bidang Kepariwisataan. Jakarta: PT Gramedia Pustaka Utama.

Mahagangga, IGAO, et. all. 2020. Tourism Evolution in Badung Regency Bali in Conference: The 5th International Conference on Climate Change, Sebelas Maret University, Indonesia, 24-25 September 2020. Research gate link. Number of DOI: $10.13140 /$ RG.2.2.34920.29449

Miles, dkk. 1992._Analisis Data Kualitatif Buku Sumber Tentang Metode-metode Baru. Jakarta: UIP.

Moleong, Lexy J., 2002. Metodologi Penelitian Kualitatif. Bandung : PT Remaja Rosdakarya.

Muliadi, I. Nyoman, And Ida Ayu Suryasih .2016. Pengelolaan Museum Arma Sebagai Daya Tarik Wisata Budaya Di Desa Ubud. Jurnal Destinasi Pariwisata 4.2

Nazir. 1988. METODE PENELITIAN. Jakarta : Ghalia Indonesia.

Permilasari, I. Nyoman Sukma Arida. 2014. Bentuk Pengelolaan Pantai Batu Bolong Sebagai Daya Tarik Wisata Surfing Di Desa Canggu, Kecamatan Kuta Utara, Kabupaten Badung. Jurnal Destinasi Pariwisata 2.2

Rahmawati, Ani. 2009. Pengelolaan Kawasan Pesisir Untuk Kegiatan Wisata Pantai Dan Perikanan Di Kecamatan Pringkuku, Kabupaten Pacitan, Provinsi Jawa Timur. Bogor.

Sudjana. 2000. Metode Statistika. Edisi Revisi. Cetakan Keenam. Bandung : Tarsito.

Sugiyono. 2003. Metode Penelitian Bisnis. Edisi 1. Bandung : Alfabeta.

Sugiyono. 2014. Metode Penelitian Pendidikan Pendekatan Kuantitatif, Kualitatif dan R\&D. Bandung : Alfabeta

Suryawan, I. B., \& Mahagangga, I. G. A. O. (2017). Penelitian Lapangan 1. Denpasar: Cakra Media dan Fakultas Pariwisata Universitas Udayana.

Terry, George R dan Leslie W . Rue . 2014. Dasar-dasar Manajemen. Jakarta : Bumi Aksara.

Undang-undang Nomor 10 Tahun 2009 Tentang Kepariwisataan. 